\title{
Erythrocyte Metabolism and Antioxidant Status of Patients with Wilson Disease with Hemolytic Anemia
}

\author{
SAVITA ATTRI, NEERAJ SHARMA, SUJEET JAHAGIRDAR, BABU RAM THAPA, AND RAJENDRA PRASAD
}

Departments of Biochemistry [S.A., N.S., R.P.] and Pediatric Gastroenterology [S.J., B.R.T.], Postgraduate Institute of Medical Education and Research, Chandigarh 160012, India

\begin{abstract}
Wilson disease (WD) is an autosomal recessive disorder due to the defect in $A T P 7 B$ gene characterized by excessive accumulation of copper in the liver with progressive hepatic damage and subsequent redistribution to various extrahepatic tissues including the brain, kidneys, and cornea. Strikingly, the total serum copper concentration is always low in WD, even though the nonceruloplasmin copper level is still expected to be high. To assess the role of free radical reactions catalyzed by non-ceruloplasmin copper, we investigated erythrocyte metabolism and oxidative stress as a mechanism for hemolysis in eight WD patients during episodes of acute hemolysis and compared them with eight follow-up cases of WD on D-penicillamine therapy and eight healthy, age-matched children. Elevated levels of non-ceruloplasmin copper were found in all the WD patients during an episode of hemolytic anemia. There was marked inhibition in erythrocyte enzymes, namely, hexokinase, total adenosine triphosphatase (ATPase), and glucose-6-phosphate dehydrogenase (G-6-PD) from WD patients compared with patients on penicillamine and healthy children, indicating altered erythrocyte metabolism during a hemolytic crisis. Antioxidant status was also found to be compromised as is evident from decreased glutathione (GSH) levels, decreased antioxidant enzymes (namely, superoxide dismutase, catalase, glutathione peroxidase, and glutathione reductase), increased lipid peroxidation, and deranged plasma antioxidants. Uric acid showed maximum decrease followed by ascorbic acid. These findings suggest that the free radical production by elevated non-ceruloplasmin copper through transition metal catalyzed reactions leads to oxidative injury resulting in altered erythrocyte metabolism and severely compromised antioxidant status of WD patients during hemolytic anemia. (Pediatr Res 59: 593-597, 2006)
\end{abstract}

$\mathrm{C}$ opper is an essential trace element required as a cofactor for a variety of enzymes including cytochrome- $c$ oxidase, tyrosinase, superoxide dismutase, dopamine- $\beta$ hydroxylase, and ceruloplasmin. Copper is required in trace amounts and is toxic when present in excess. Because the dietary intake exceeds the body's requirement for the copper, the body requires an efficient means of excretion for the metal. Copper accumulates to toxic levels in cells in several human disorders, causing cellular injury and progressive damage of the tissues (1). WD, an autosomal recessive disorder due to

Received July 20, 2005; accepted November 28, 2005.

Correspondence: Rajendra Prasad, Ph.D., Department of Biochemistry, Postgraduate Institute of Medical, Education and Research, Chandigarh 160012, India; e-mail: fateh1977@yahoo.com

This work was supported by Indian Council of Medical Research (63/167/2001-BMS), New Delhi, India.

DOI: 10.1203/01.pdr.0000203098.77573.39 defect in the $A T P 7 B$ (2) gene, is a dramatic illustration of dysregulation of copper metabolism in which disturbed export of copper from hepatocytes to bile and its decreased incorporation into ceruloplasmin results in an accumulation of copper in a number of organs particularly liver and brain (3). Despite the low total serum copper and ceruloplasmin, the nonceruloplasmin copper levels are found significantly higher in WD patients (3). Massive amounts of hepatic copper are intermittently released into circulation during acute episodes of hemolysis, resulting in transient elevations of erythrocytic and urinary copper and non-ceruloplasmin copper level is comparable with that seen in acute copper poisoning (4). Free radical production by reactions involving plasma nonceruloplasmin copper has been proposed as the cause of acute hemolysis associated with severe liver damage in WD (5). If copper ions released from the liver into the blood catalyze the generation of free radicals, subsequently the consumption of blood antioxidants might be a possible initial event. A variety of other pathophysiological mechanisms have been proposed including inhibition of red blood cell (RBC) enzymes (6) and direct erythrocyte membrane damage resulting in reduced ATP utilization (7) that contribute to hemolysis; however, the information regarding the molecular basis of copper-induced hemolysis in relation to red cell metabolism and antioxidant status is scattered. D-Penicillamine is considered the gold standard for WD therapy and acts by reductive chelation (8), and within a few weeks to months, it brings the level of copper to a subtoxic threshold and allows tissue repair. It was therefore a reasonable line of investigation to examine closely the red cell metabolism and antioxidant profile of WD patients with hemolytic anemia and to compare them with a group of WD patients on D-penicillamine therapy and healthy agematched controls.

\section{MATERIALS AND METHODS}

Reagents. All reagents used in present study were of the highest quality procured from Sigma Chemical Co. (St. Louis, MO).

Abbreviations: G-6-PD, glucose-6 phosphate dehydrogenase; GSH, reduced glutathione; TRAP, total radical trapping antioxidant parameter; WD, Wilson disease 
Subjects. Protocol approval was obtained from the ethical committee of Postgraduate Institute of Medical Education and Research, Chandigarh, and informed consent was obtained from the parents of the children. We investigated eight newly diagnosed WD patients with accompanying hemolytic crisis before starting penicillamine therapy (five boys and three girls; mean age, $13.8 \mathrm{y}$ ), eight WD patients on penicillamine therapy during their follow-up (six boys and two girls; mean age, $10 \mathrm{y}$ ), and eight age and sexmatched healthy controls (five boys and three girls; mean age, 12 y). The diagnosis of WD was confirmed based on clinical and laboratory findings, i.e. low serum ceruloplasmin levels $(<20 \mathrm{mg} / \mathrm{dL})$ and high urinary copper excretion both before $(>80 \mu \mathrm{g} / \mathrm{d})$ and after $(>1200 \mu \mathrm{g} / \mathrm{d})$ penicillamine. Hemolysis was evidenced by high serum free copper, anemia (low $\mathrm{Hb}$ content), hyperbilirubinemia, and negative direct and indirect Coombs tests.

Collection of blood samples and separation of erythrocytes. The venous blood was drawn with a 23-gauge needle and quickly aliquoted into Vacutainers containing heparin to prevent coagulation for antioxidant studies. The samples were kept on ice during transportation to the laboratory. Erythrocytes were isolated from the blood using Ficoll-Paque (Amersham Biosciences) density gradient centrifugation per manufacturer's instructions. The samples were centrifuged at $1000 \times g$ for $20 \mathrm{~min}$ at $4{ }^{\circ} \mathrm{C}$. The supernatant containing the Ficoll-Paque gradient and white blood cells were aspirated and discarded. The remaining pellet was washed with phosphate-buffered saline (PBS) ( $\mathrm{pH}$ 7.4). To keep the number of erythrocytes constant in all samples, they were diluted to a concentration equivalent to a hematocrit of $40 \%$ using PBS. This value was chosen because it is in the range of children aged $6-15$ y. For ATPase assay, the pellet was washed three times with isotonic Tris $\mathrm{HCl}$ buffer $(0.172 \mathrm{~mol} / \mathrm{L}, \mathrm{pH} 7.6)$ and suspended in same buffer.

Assays to detect functional integrity of RBC membrane. The percentage of hemolysis was estimated following the procedure of Tanaka and Nakai (9). In brief, $0.4 \%$ ammonium hydroxide solution was prepared. The erythrocytes from different groups were centrifuged at $1500 \mathrm{rpm}$ for $10 \mathrm{~min}$, and the supernatant was separated to determine the degree of hemolysis. The supernatant and the original erythrocyte suspension were diluted with four volumes of $0.4 \%$ ammonium hydroxide, and the absorbance at $540 \mathrm{~nm}$ was measured. The relative ratio of absorbance of diluted supernatant to that of diluted original suspension was expressed as the percentage of hemolysis. Total ATPase (EC 3.6.1.3) activity was measured in red cell hemolysate with slight modification and the inorganic phosphate liberated as a result of hydrolysis of ATP was measured per Tashima (10). Hemolysate for ATPase was prepared by mixing erythrocyte suspension in saponin solution (1:10). Hexokinase (EC 2.7.1.1) was measured spectrophotometrically as described by Beutler (11). Activity was detected in hemolysate prepared by mixing erythrocyte suspension with $\beta$-mercaptoethanol-ethylenediaminetetraacetic acid (EDTA) stabilizing solution $(0.05 \mathrm{~mL}$ of $\beta$-mercaptoethanol and $10 \mathrm{~mL}$ of neutralized $10 \%$ EDTA, volume made to IL). Hexokinase activity is directly related to the production of NADPH. So enzyme activity was calculated by using molar extinction coefficient of $6.22 \times 10^{3} / \mathrm{cm} / \mathrm{molar}$ concentration of NADPH (nicotinamide adenine dinucleotide phosphate, oxidized and reduced form). G-6-PD (EC 1.1.1.49) activity was determined by the method described by Varley (12). Hemolysate used for detection of G-6-PD activity was prepared in digitonin. Activity was expressed as IU/g of hemoglobin (Hb). Concentration of $\mathrm{Hb}$ in packed RBCs was measured colorimetrically.

Assays to study antioxidant defense system of erythrocytes and plasma. GSH in erythrocyte suspension was estimated by 5,5'-dithiobis-(2nitrobenzoic) acid (DTNB) method of Beutler et al. (13). Membrane peroxidative damage in erythrocytes was determined in terms of malondialdehyde production as described by Jain (14). Antioxidant enzyme assays were carried out using red cell hemolysate. Superoxide dismutase (EC 1.15.1.1) was estimated by the method of Kono (15) based on the inhibitory effect of superoxide dismutase on the reduction of nitroblue tetrazolium dye by the superoxide anions generated by photo-oxidation of hydroxylamine hydrochloride. Activity of catalase (EC 1.11.1.6) was measured by adopting the method of Luck (16). Glutathione peroxidase (EC 1.11.1.9) and glutathione reductase (EC 1.6.4.2) were assayed by the method of Flohe and Gunzler (17) and Carlberg and Mannervik (18), respectively. The plasma ascorbic acid was determined spectrophotometrically with 2,4-dinitrophenylhydrazine to form the red bis-hydrazone, which can be measured at $520 \mathrm{~nm}$ (19). Uric acid was estimated using uricase method (20). Plasma sulfhydryl groups were measured by the method of Sedlak and Lindsay (21). Plasma $\alpha$-tocopherol levels were measured using high-performance liquid chromatography (22). Total radical trapping antioxidant parameters (TRAP) was calculated from concentrations of (in decreasing order of quantitative importance) uric acid, sulfhydryl groups, ascorbate, and $\alpha$-tocopherol according to the formula: TRAP $=$ 1.3 (uric acid) +0.33 (sulfhydryl groups) +1.7 (ascorbate) $+2.0(\alpha$ tocopherol) (23).

Copper and ceruloplasmin. Copper studies were conducted in all the subjects under investigation. Serum, urinary, and erythrocyte copper levels were monitored on atomic absorption spectrophotometer (Perkin Elmer) using a hollow cathode lamp of copper at $324.8 \mathrm{~nm}$. Serum ceruloplasmin activity was measured as copper oxidase using $p$-phenylenediamine dihydrochloride as a substrate (24). Non-ceruloplasmin copper was estimated from serum copper and ceruloplasmin as described by Prasad et al. (25).

Statistical analysis. The statistical significance of differences between groups was evaluated with an unpaired $t$ test.

\section{RESULTS}

Clinical and laboratory findings. As shown in Table 1, hemolytic crisis in WD patients was evident from increased plasma $\mathrm{Hb}$ levels, decreased hematocrit, and anemia. Liver function tests were deranged including increased alanine aminotransferase, aspartate aminotransferase, and bilirubin, however, alkaline phosphatase (ALP) activity showed a decline. A significant increase of copper was observed in serum, urine, and erythrocytes of WD patients. Conversely, the patients on penicillamine therapy and age-matched controls had normal values. Similarly, non-ceruloplasmin copper levels reached to $105.8 \pm 19.0 \mu \mathrm{g} / \mathrm{dL}$ in WD patients, whereas the patients on penicillamine and healthy controls had normal serum nonceruloplasmin copper.

Structural and functional integrity of erythrocytes. The release of free copper into the circulation was associated with a significantly increased percentage of hemolysis of erythrocytes of WD patients compared with healthy controls and WD patients on penicillamine therapy. Because increased hemolysis of erythrocytes indicates their increased fragility, activity of total ATPase, which is a membrane enzyme, was measured

Table 1. Summary of clinical and laboratory data

\begin{tabular}{|c|c|c|c|}
\hline Subjects & $\begin{array}{l}\text { WD patients } \\
\text { with hemolytic } \\
\text { anemia }\end{array}$ & $\begin{array}{l}\text { WD patients } \\
\text { on penicillamine }\end{array}$ & Controls \\
\hline $\mathrm{M} / \mathrm{F}$ & $5 / 3$ & $6 / 2$ & $5 / 3$ \\
\hline Age (y) & $13.8 \pm 3.2$ & $10 \pm 4.0$ & $12 \pm 3.1$ \\
\hline ALT (IU/L) & $97 \pm 15$ & $29 \pm 11$ & $10.2 \pm 4.3$ \\
\hline AST (IU/L) & $344 \pm 58 * *$ & $38 \pm 12$ & $12.2 \pm 4.0$ \\
\hline ALP (IU/L) & $40 \pm 24.47 \dagger^{*}$ & $77 \pm 20.46$ & $99 \pm 15.38$ \\
\hline Bilirubin (mg/dL) & $15.7 \pm 2.3 * *$ & $1.1 \pm 0.9$ & $0.6 \pm 0.3$ \\
\hline $\mathrm{Hb}(\mathrm{g} / \mathrm{dL})$ & $6.8 \pm 2.1 * *$ & $12.7 \pm 2.7$ & $13.2 \pm 1.9$ \\
\hline Plasma $\mathrm{Hb}(\mathrm{mg} / \mathrm{dL})$ & $11 \pm 2.1 * *$ & $3 \pm 1.9$ & $2 \pm 1.7$ \\
\hline $\mathrm{PCV}$ & $18.5 \pm 6.0^{* *}$ & $36.1 \pm 9.0$ & $40.0 \pm 3.0$ \\
\hline$\%$ Hemolysis & $95 \pm 1.57 * *$ & $0.72 \pm 0.07$ & $0.62 \pm 0.10$ \\
\hline $\begin{array}{l}\text { Ceruloplasmin } \\
\quad(\mathrm{mg} / \mathrm{dL})\end{array}$ & $5.8 \pm 3.1 * *$ & $82 \pm 4.7$ & $32.0 \pm 8.1$ \\
\hline $\begin{array}{l}\text { Erythrocyte copper } \\
\qquad(\mu \mathrm{g} / \mathrm{dL})\end{array}$ & $350 \pm 45^{* *}$ & $93 \pm 31$ & $80 \pm 21$ \\
\hline $\begin{array}{l}\text { Serum copper } \\
\quad(\mu \mathrm{g} / \mathrm{dL})\end{array}$ & $140 \pm 30.1^{*}+$ & $30.1 \pm 8.2$ & $102 \pm 25.9$ \\
\hline $\begin{array}{l}\text { Free copper } \\
\qquad(\mu \mathrm{g} / \mathrm{dL})\end{array}$ & $105.8 \pm 19.0^{* *}$ & $5.6 \pm 1.7$ & $4.8 \pm 1.2$ \\
\hline $\begin{array}{l}\text { Urine copper } \\
\qquad(\mu \mathrm{g} / \mathrm{dL})\end{array}$ & $\begin{array}{r}\text { Prepen } 632 \pm 198 \S^{*} \\
\text { Postpen } 1677 \pm 255^{* *}\end{array}$ & $310 \pm 56$ & $22.7 \pm 3.8$ \\
\hline
\end{tabular}

Data are expressed as mean $\pm \mathrm{SD}, n=8$ for each group. Free copper was calculated as described in "Methods." Urine copper was estimated in patients with hemolytic crisis both before and after penicillamine challenge. The first symbol refers to statistical significant difference compared with WD patients on penicillamine and the other compared with age-matched controls.

ALT, alanine aminotransferase; AST, aspartate aminotransferase; ALP, alkaline phosphatase; PCV, packed cell volume; Prepen, pre-penicillamine; Postpen, post-penicillamine.

$* p<0.0001 ; \dagger p<0.01 ; \ddagger p<0.05 ; \S p<0.001$. 
(Table 2) and was found to be significantly inhibited in WD patients compared with follow-up cases and healthy children. Glycolysis is the principal source of energy for RBCs. To see the effect of free copper in limiting the metabolic capacity of the erythrocytes, hexokinase activity was estimated, which is one of the rate-limiting enzymes in glycolysis. As shown in Table 2, we observed a marked inhibition of hexokinase activity in WD patients with hemolytic crisis compared with healthy controls and WD patients on penicillamine therapy. Generation of NADPH through G-6-PD reactions is an essential step for the maintenance of GSH level and protects the cell from oxidative injury. So G-6-PD activity was estimated and was found to be significantly inhibited in WD patients with hemolytic anemia compared with follow-up cases and healthy children (Table 2). From these observations it was evident that the structural and functional integrity of RBCs in WD patients of hemolytic anemia was severely compromised. D-Penicillamine maintained the status quo as that of healthy controls.

Antioxidant status of erythrocytes and plasma. Antioxidant profile of erythrocytes in WD patients with hemolytic anemia was drastically altered, as shown in Table 3. As expected, GSH was found to be significantly depleted in WD patients with hemolytic anemia compared with follow-up patients and healthy controls. Superoxide dismutase, catalase, and peroxidase enzymes were measured in erythrocytes as they provide defense against reactive oxygen intermediates. As shown in Table 3, superoxide dismutase, the major defense system against superoxide radicals, was significantly low in WD patients with hemolytic crisis compared with follow-up cases on penicillamine therapy and healthy controls. Catalase and glutathione peroxidase enzymes also showed a decrease in red cell hemolysates of WD patients with hemolytic crisis. Both enzyme activities were well preserved in WD follow-up patients when compared with healthy controls. The enzyme GSH, which uses NADPH to generate GSH, was found to be significantly decreased in WD patients with hemolytic crisis compared with healthy controls. Glutathione reductase activity in WD patients on penicillamine was equivalent to that of healthy, age-matched controls. One of the damaging mechanisms of reactive oxygen species is initiation of lipid peroxidation. We observed a significant increase in malondialdehyde levels in RBCs of WD patients with hemolytic crisis com-

Table 2. Percentage of inhibition of ATPase, hexokinase, and G-6-PD in WD patients with hemolytic anemia

\begin{tabular}{cccc}
\hline & $\begin{array}{c}\text { ATPase } \\
(\mu \mathrm{mol} \mathrm{Pi} \\
\text { Subject }\end{array}$ & $\begin{array}{c}\text { Hexokinase } \\
\text { liberated/g Hb/2h })\end{array}$ & $\begin{array}{c}\text { G-6-PD } \\
(\mathrm{IU} / \mathrm{g} \mathrm{Hb})\end{array}$ \\
\hline WD patients with & $87.3 \pm 14.8 * *$ & $0.64 \pm 0.13 \dagger \dagger$ & $8.23 \pm 1.9+\ddagger$ \\
hemolytic anemia & $27.65 \%$ & $50.29 \%$ & $25.30 \%$ \\
WD patients on & $115.7 \pm 12.3$ & $1.26 \pm 0.15$ & $10.38 \pm 1.12$ \\
D-penicillamine & $4.28 \%$ & $3.67 \%$ & 5.7 \\
Controls & $121.4 \pm 17.8$ & $1.32 \pm 0.18$ & $10.95 \pm 1.02$ \\
\hline
\end{tabular}

Data are expressed as mean $\pm \mathrm{SD}, n=8$ for each group. The first symbol refers to statistically significant difference compared with WD patients on penicillamine and the other compared with age-matched controls.

$* p<0.001 ; \dagger p<0.0001 ; \neq p<0.01$.
Table 3. Erythrocyte antioxidant concentrations and lipid peroxidation

\begin{tabular}{|c|c|c|c|}
\hline Subjects & $\begin{array}{l}\text { WD patients } \\
\text { with hemolytic } \\
\text { anemia }\end{array}$ & $\begin{array}{l}\text { WD patients on } \\
\text { D-penicillamine }\end{array}$ & Controls \\
\hline GSH (mg/100 mL RBC) & $40.2 \pm 17.0^{* \dagger}$ & $64.6 \pm 20.98$ & $70.1 \pm 19.37$ \\
\hline $\begin{array}{l}\text { Superoxide dismutase } \\
\text { (U/g Hb) }\end{array}$ & $2178 \pm 465^{* \dagger}$ & $2901 \pm 375$ & $3050 \pm 317$ \\
\hline $\begin{array}{l}\text { Catalase }(\mu \mathrm{mol} / \mathrm{min} / \mathrm{g} \\
\mathrm{Hb})\end{array}$ & $0.95 \pm 0.41$ 抹 & $1.48 \pm 0.40$ & $1.59 \pm 0.49$ \\
\hline $\begin{array}{l}\text { Glutatione peroxidase } \\
\text { (nmol/min/g Hb) }\end{array}$ & $210 \pm 69 * \dagger$ & $321 \pm 61$ & $333 \pm 76$ \\
\hline $\begin{array}{l}\text { Glutathione reductase } \\
\qquad(\mu \mathrm{mol} / \mathrm{min} / \mathrm{g} \mathrm{Hb})\end{array}$ & $14.1 \pm 4.6^{* *}$ & $22.3 \pm 5.1$ & $20.7 \pm 3.9$ \\
\hline $\begin{array}{l}\text { Lipid peroxidation } \\
\text { (malondialdehyde } \\
\mathrm{nmol} / \mathrm{mL} \text { packed } \\
\text { cells) }\end{array}$ & $2.6 \pm 0.7 \ddagger *$ & $1.3 \pm 0.7$ & $1.2 \pm 0.3$ \\
\hline
\end{tabular}

Data are expressed as mean $\pm \mathrm{SD}, n=8$ for each group. The first symbol refers to the statistically significant difference compared with WD patients on penicillamine and the other compared with age-matched controls.

$* p<0.01 ; \dagger p<0.001 ; \ddagger p<0.05$.

pared with follow-up WD patients and healthy controls (Table 3).

Uric acid and ascorbic acid are among the most important water-soluble antioxidants. Uric acid contributes two thirds of the antioxidant capacity of human plasma. Uric acid showed the maximum decrease $(76 \%)$ in WD patients with hemolytic anemia compared with control subjects (Fig. 1). Ascorbic acid values were also reduced significantly $(19.25 \pm 6.5 \mu \mathrm{mol} / \mathrm{L})$ compared with healthy controls $(56.9 \pm 13.7 \mu \mathrm{mol} / \mathrm{L} p<$ $0.0001)$. Both urate and ascorbate levels were maintained near normal levels in WD patients on penicillamine therapy. Similarly, sulfhydryl groups were also found to be significantly decreased $(p<0.0001)$ in patients of WD with hemolytic anemia. Among plasma antioxidants studied, $\alpha$-tocopherol is major chain-breaking antioxidant in the lipid phase, which also showed significant decline $(p<0.05)$. Plasma antioxidant status was well preserved in WD patients on D-penicillamine therapy. TRAP of human plasma was also found to be significantly decreased in WD patients with hemolytic anemia.

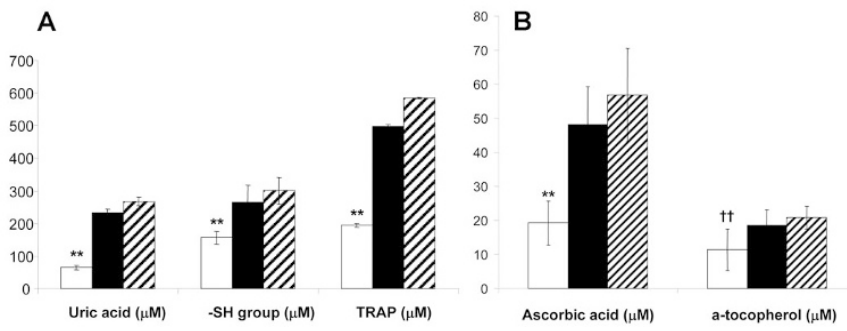

Figure 1. Plasma antioxidant levels. Data were obtained from WD patients with hemolytic crisis (open columns) and WD patients on penicillamine treatment (filled columns) and healthy, age-matched children (hatched columns). SH groups, sulfhydryl groups. TRAP values were calculated stoichiometrically from the concentrations of plasma antioxidants as described in "Methods." Data are expressed as mean $\pm \mathrm{SD}, n=8$ for each group. First symbol refers to statistically significant difference compared with WD patients on penicillamine and the other compared with age-matched controls. 


\section{DISCUSSION}

WD is an autosomal recessive disorder of $A T P 7 B$ gene characterized by defective biliary excretion of copper in bile and its incorporation into ceruloplasmin resulting in copper accumulation to toxic levels in liver with progressive hepatic damage and subsequent redistribution to various extrahepatic tissues including the brain, eyes, kidneys, blood, and other organs (1). We have shown markedly increased levels of serum non-ceruloplasmin copper as well as erythrocytic copper in WD patients with hemolytic anemia. A review of such patients in the literature suggests that, rather than having low serum copper levels, patients with hemolysis accompanying WD have very high serum copper levels (5). A significant increase in the percentage of hemolysis in WD patients indicates the deleterious effects of free copper and possible mechanisms might include oxidant injury, inhibition of red cell enzymes, and, more directly, the adverse effects on membrane. It is very interesting that the plasma $\mathrm{Hb}$ in WD patients with hemolytic anemia reached $11 \mathrm{mg} / \mathrm{dL}(2 \mu \mathrm{mol} / \mathrm{L})$. This is a level that has been associated with scavenging of nitric oxide by plasma $\mathrm{Hb}$, which would deplete the body's natural antioxidant capacity supplied normally by nitric oxide. It should be noted that hemolysis might be involved as a part of the mechanism of oxidant stress in these patients (26). Low ALP activity is an important and specific finding for fulminant hepatic failure of WD patients, but its mechanism is still unknown. Hoshino et al. (27) suggested that hydroxyl radicals or, alternatively, alkoxyl or peroxide radicals induced by Fenton reaction, may markedly reduce ALP activity through the $\mathrm{Mg}^{2+}$ site of the ALP molecule. We have shown 27.65\% inhibition of ATPase activity in our WD patients during hemolytic anemia. Inhibition of ATPase might cause configurational change in erythrocytes making them more susceptible to hemolysis by free copper (28). Hexokinase was also found to be inhibited (50.29\%) in our patients. The copper has been reported to be most effective in inhibiting hexokinase and hence glycolysis of rat brain extract, suggesting pathophysiological importance in copper poisoning and in WD (29).

We have observed significant decline of RBC GSH in WD patients with hemolytic crisis. GSH might have been depleted after excessive conjugation with reactive oxygen species, excess copper or with reactive intermediates like those formed during lipid peroxidation. Furthermore, excess copper inhibited the activity of both G-6-PD and glutathione reductase, both of which are necessary for the reduction of oxidized glutathione (GSSG) to GSH. Each of these effects would tend to decrease the reduced GSH content of erythrocytes and make them more vulnerable to oxidative effects of copper as erythrocyte GSH plays an important role in the preservation of red cell integrity, particularly under stressful situations. GSH protects against lipid peroxidation by maintaining protein thiols and consequently $\alpha$-tocopherol in the reduced state (30). Lipid peroxidation was significantly greater in erythrocytes of WD patients during a hemolytic episode compared with healthy controls and WD follow-up patients on D-penicillamine. It has been widely recognized that trace amounts of transition metals including copper and iron play a major role in oxidant-induced tissue injury through participation in the generation of hydroxyl radicals, which rapidly react with polyunsaturated fatty acid residues of cell membranes and facilitates lipid peroxidation (31). Our finding is in contrast to that of Ogihara et al. (32), who did not observe increased levels of lipid peroxidation along with no change in plasma $\alpha$-tocopherol levels. However, in the present study, increased lipid peroxidation is supported by decreased plasma $\alpha$-tocopherol levels. von Herbay et al. (33) also reported 40\% lower serum $\alpha$-tocopherol levels in their WD patients with a high copper burden. A decrease in $\alpha$-tocopherol might be due to its consumption during free radical scavenging as well as to a decrease in GSH and ascorbic acid content as both are involved in the recycling of vitamin E. It is also possible that copper ions catalyze the oxidation of ascorbic acid or sulfhydryl groups, in the process reducing molecular oxygen to generate reduced oxygen metabolites such as superoxide and hydrogen peroxide (34). Superoxide dismutases, catalases, and glutathione peroxidases constitute a mutually supportive team of enzymes, which provide a defense against reactive oxygen species. We observed inhibition of all three enzymes involved. Superoxide radicals when produced in excess may inactivate the $\mathrm{H}_{2} \mathrm{O}_{2}$ scavengers (35), and mechanisms involving oxidation of selenocysteine residue at the active site have been proposed. The decreased activities of catalase and glutathione peroxidase might have resulted in efficient removal of $\mathrm{H}_{2} \mathrm{O}_{2}$ and its buildup. Excess $\mathrm{H}_{2} \mathrm{O}_{2}$ present in the cellular milieu may inactivate superoxide dismutase (36).

In human plasma, ascorbic and uric acid are among the most widely cited forms of water-soluble antioxidants and appear to serve as the main defense against oxidizing species in the aqueous phase (37). Uric acid showed the greatest decrease among various plasma antioxidants in WD patients. Uric acid, a product of purine metabolism in humans, may act as a sacrificial antioxidant against hydroxyl and peroxyl radicals as well as other hazardous oxidants. Uric acid, if consumed as an antioxidant, is destroyed by bacteria in the intestine. However, inosine, which is a naturally occurring substance, increases plasma uric acid levels (38). Plasma ascorbate and sulfhydryl groups also showed a severe decline in WD patients with hemolytic crisis compared with other subjects involved in the study. The decrease of ascorbic acid and sulfhydryl groups in patients with WD may have resulted from their antioxidative degradation. However, in the presence of transition metals, ascorbic acid and sulfhydryl groups are readily oxidized to generate reactive oxygen species and other radical species (34). Accordingly, it is also possible that ascorbic acid and sulfhydryl groups acted as pro-oxidants rather than antioxidants in WD patients during hemolytic crisis. In recent studies, the TRAP assay has provided useful information about plasma antioxidant activity in newborns (23) and patients with cystic fibrosis (39). Plasma antioxidant capacity calculated as TRAP was significantly decreased in WD patients during a hemolytic episode.

It has been observed that all the red cell enzymes and plasma antioxidants were well preserved in WD follow-up patients on penicillamine therapy as in control healthy subjects. As we know that D-penicillamine is a chelator of copper, 
normal levels of copper in follow-up patients were associated with well-preserved metabolism and antioxidant status of erythrocytes. Moreover, this group of WD patients on penicillamine therapy had no chief complaints of hemolytic crisis. In conclusion, we have provided evidence of the association between copper-induced oxidative injury to erythrocytes of WD patients and hemolytic anemia. An antioxidant that could support the GSH system and chelate reactive intermediates as well as excess copper so as to take care of oxidative injury in WD patients caused by free copper during hemolytic episode deserves investigation.

\section{REFERENCES}

1. Scheinberg IH, Sternlieb I 1984 Wilson's Disease. WB Saunders, Philadelphia, pp 25-37.

2. Petrukhin K, Fischer SG, Pirastu M, Tanzi RE, Chernov I, Devoto M, Brzustowicz LM, Cayanis E, Vitale E, Russo JJ 1993 Mapping, cloning and genetic characterization of the region containing the Wilson disease gene. Nat Genet 5:338-343

3. Stremmel W, Meyerrose KW, Niederau C, Hefter H, Kreuzpaintner G, Strohmeyer G 1991 Wilson disease: clinical presentation, treatment, and survival. Ann Intern Med 115:720-726

4. Deiss A, Lee GR, Cartwright GE 1970 Hemolytic anemia in Wilson's disease. Ann Intern Med 73:413-418

5. Forman SJ, Kumar KS, Redeker AG, Hochstein P 1980 Hemolytic anemia in Wilson disease: clinical findings and biochemical mechanisms. Am J Hematol 9:269-275

6. Boulard M, Blume KG, Beutler E 1972 The effect of copper on red cell enzyme activities. J Clin Invest 51:459-461

7. Feig SA, Segel GB, Shohet SB, Nathan DG 1972 Energy metabolism in human erythrocytes II. Effect of glucose depletion. J Clin Invest 51:1547-1554

8. Bavdekar AR 2004 Therapeutic and management challenges in Wilson's Disease. J Gastroenterol Hepatol 19:S391-S395

9. Tanaka R, Nakai K 1977 Hemolysis and morphological changes in rat erythrocytes with mercurials. Jpn J Pharmacol 27:413-419

10. Tashima Y 1975 Removal of protein interference in Fiske-Subbarow method by sodium dodecyl sulphate Anal Biochem 69:410-414

11. Beutler E 1984 Red Cell Metabolism: A Manual of Biochemical Methods. Grune and Stratton, Orlando, FL, pp 38-39.

12. Varley H, Gowenlock AH, Bell M 1980 Glucose-6-phosphate dehydrogenase. In: Varley H, Gowenlock A (eds) Varley's Practical Clinical Biochemistry. Whitefriar Press, Tonbridge, pp 729-731.

13. Beutler E, Duron O, Kelly BM 1963 Improved method for the determination of blood glutathione. J Lab Clin Med 61:882-888

14. Jain SK 1988 Evidence for membrane lipid peroxidation during the in vivo aging of human erythrocytes. Biochim Biophys Acta 937:205-210

15. Kono Y 1978 Generation of superoxide radical during autooxidation of hydroxylamine and an assay for superoxide dismutase. Arch Biochem Biophys 186-189

16. Luck H 1963 A spectrophotometric method for the estimation of catalase. In: Bergmeyer HV (ed) Methods of Enzymatic Analysis. Verlag Chemie, Weinheim, pp $886-888$
17. Flohe L, Gunzler WA 1984 Assays of glutathione peroxidase. Methods Enzymol 105:114-121

18. Carlberg I, Mannervik B 1985 Glutathione reductase. In: Meister A (ed) Methods in Enzymology. Academic Press, New York, pp 484-490.

19. Roe JM, Kuether CA 1943 Detection of ascorbic acid in whole blood and urine through the 2,4-DNPH derivative of dehydroascorbic acid. J Biol Chem 147:399407

20. Duncan PH, Gochman N, Cooper T, Smith E, Bayse D 1982 A candidate reference method for uric acid in serum. I. Optimization and evaluation. Clin Chem 28:284 290

21. Sedlak J, Lindsay RH 1968 Estimation of total, protein-bound and nonprotein sulfhydryl groups in tissue with Ellman's reagent. Anal Biochem 25:192-205

22. Lee BL, Chua SC, Ong HY, Ong CN 1992 High-performance liquid chromatographic method for routine determinations of vitamins $\mathrm{A}$ and $\mathrm{E}$ and beta-carotene in plasma. J Chromatogr 581:41-47

23. Lindeman JH, van Zoeren-Grobben D, Schrijver J, Speek AJ, Poorthuis BJ, Berger HM 1989 The total free radical trapping ability of cord blood plasma in preterm and term babies. Pediatr Res 26:20-24

24. Ravin HA 1961 An improved colorimetric enzymatic assay of ceruloplasmin. J Lab Clin Med 58:161-168

25. Prasad R, Kaur G, Walia BN 1998 A critical evaluation of copper metabolism in Indian Wilson's disease children with special reference to their phenotypes and relatives. Biol Trace Elem Res 63:153-155

26. Rother RP, Bell L, Hillmen P, Gladwin MT 2005 The clinical sequelae of intravascular hemolysis and extracellular plasma hemoglobin: a novel mechanism of human disease. JAMA 293:1653-1662

27. Hoshino T, Kumasaka K, Kawano K, Yamagishi F, Koyama I, Fujimori-Arai Y, Nakajima T, Komoda T 1995 Low serum alkaline phosphatase activity associated with severe Wilson's disease. Is the breakdown of alkaline phosphatase molecules caused by reactive oxygen species? Clin Chim Acta 238:91-100

28. Bowler K, Duncan CJ 1970 The effect of copper on membrane enzymes. Biochim Biophys Acta 196:116-119

29. Lai JC, Blass JP 1984 Neurotoxic effects of copper: inhibition of glycolysis and glycolytic enzymes. Neurochem Res 9:1699-1710

30. Palamanda JR, Kehrer JP 1993 Involvement of vitamin E and protein thiols in the inhibition of microsomal lipid peroxidation by glutathione. Lipids 28:427-431

31. Halliwell B, Gutteridge JM 1984 Oxygen toxicity, oxygen radicals, transition metals and disease. Biochem J 219:1-14

32. Ogihara H, Ogihara T, Miki M, Yasuda H, Mino M 1995 Plasma copper and antioxidant status in Wilson's disease. Pediatr Res 37:219-226

33. von Herbay A, de Groot, H, Hegi U, Stremmel W, Strohmeyer G, Sies H 1994 Low vitamin $\mathrm{E}$ content in plasma of patients with alcoholic liver disease, hemochromatosis and Wilson's disease. J Hepatol 20:41-46

34. Hochstein P, Kumar KS, Forman SJ 1980 Lipid peroxidation and the cytotoxicity of copper. Ann N Y Acad Sci 355:240-248

35. Blum J, Fridovich I 1985 Inactivation of glutathione peroxidase by superoxide radical. Arch Biochem Biophys 240:500-508

36. Blech DM, Borders CL Jr 1983 Hydroperoxide anion, $\mathrm{HO}-{ }_{2}$, is an affinity reagen for the inactivation of yeast $\mathrm{Cu}, \mathrm{Zn}$ superoxide dismutase: modification of one histidine per subunit. Arch Biochem Biophys 224:579-586

37. Halliwell B, Gutteridge JM 1990 The antioxidants of human extracellular fluids. Arch Biochem Biophys 280:1-8

38. Spitsin S, Hooper DC, Leist T, Streletz LJ, Mikheeva T, Koprowskil H 2001 Inactivation of peroxynitrite in multiple sclerosis patients after oral administration of inosine may suggest possible approaches to therapy of the disease. Mult Scler 7:313-319

39. Langley SC, Brown RK, Kelly FJ 1993 Reduced free-radical trapping capacity and altered plasma antioxidant status in cystic fibrosis. Pediatr Res 33:247-250 